\title{
Effects of Tocotrienol and Lovastatin Combination on Osteoblast and Osteoclast Activity in Estrogen-Deficient Osteoporosis
}

\author{
Saif Abdul-Majeed, Norazlina Mohamed, and Ima-Nirwana Soelaiman \\ Department of Pharmacology, Faculty of Medicine, Universiti Kebangsaan Malaysia, Jalan Raja Muda Abdul Aziz, \\ 50300 Kuala Lumpur, Malaysia \\ Correspondence should be addressed to Ima-Nirwana Soelaiman, imasoel@medic.ukm.my
}

Received 31 May 2012; Revised 12 July 2012; Accepted 13 July 2012

Academic Editor: Ahmad Nazrun Shuid

Copyright ( $) 2012$ Saif Abdul-Majeed et al. This is an open access article distributed under the Creative Commons Attribution License, which permits unrestricted use, distribution, and reproduction in any medium, provided the original work is properly cited.

Statins are HMGCoA reductase inhibitors and had been demonstrated to stimulate bone formation in rodents after high oral doses. Observational studies on patients treated with oral statins were varied. Delta-tocotrienol had been found to stimulate the cleavage of HMGCoA reductase and inhibit its activity. Tocotrienols were found to have both catabolic and anabolic effects on bone in different animal models of osteoporosis. The current study aimed to ascertain the effects of delta-tocotrienol and lovastatin combination on biochemical and static bone histomorphometric parameters in a postmenopausal rat model at clinically tolerable doses. 48 Sprague Dawley female rats were randomly divided into 6 groups: (1) baseline control group; (2) sham-operated control group; (3) ovariectomised control group; (4) ovariectomised and $11 \mathrm{mg} / \mathrm{kg}$ lovastatin; (5) ovariectomised and $60 \mathrm{mg} / \mathrm{kg}$ deltatocotrienol; (6) ovariectomised and $60 \mathrm{mg} / \mathrm{kg}$ delta-tocotrienol $+11 \mathrm{mg} / \mathrm{kg}$ lovastatin. These treatments were given daily via oral gavage for 8 weeks. Delta-tocotrienol plus lovastatin treatment significantly increased bone formation and reduced bone resorption compared to the other groups. Therefore, the combined treatment may have synergistic or additive effects and have the potential to be used as an antiosteoporotic agent in patients who are at risk of both osteoporosis and hypercholesterolemia, especially in postmenopausal women.

\section{Introduction}

Osteoporosis is known as a silent age-related disorder, and it is considered as a major public health problem. Patients with osteoporosis have decreased bone density and microarchitectural disruption of bone tissue, leading to skeletal fragility and fractures. Postmenopausal osteoporosis is the most common type associated with high bone turnover and is due to estrogen deficiency [1]. Current available therapies are effective in the prevention of bone loss by stabilizing the bone mass through inhibition of osteoclast activity, but they are not favored to treat established osteoporosis where there is a need to increase bone volume. The United States Food and Drug Administration approved parathyroid hormone (Teriparatide) in 2002 as the first bone anabolic agent that can reduce the risk of osteoporotic fractures and increase bone mineral density [2]. However, the use of parathyroid hormone is associated with some drawbacks such as daily injection, and the possibility of tumorigenesis [3]. The identification of a well-tolerated anabolic agent that can increase bone formation and restore bone strength would represent a major therapeutic breakthrough in the treatment of any form of bone loss.

3-hydroxy-3-methylglutaryl coenzyme A (HMGCoA) reductase catalyzes the conversion of HMGCoA to mevalonic acid. Statins are competitive and reversible inhibitors of HMGCoA reductase. They are safely used as cholesterollowering agents and have pleiotropic actions in various systems such as the cardiovascular system, immune system, and nervous system [4]. Lovastatin is a prodrug and is converted to the active open-ring acid from its lactone by esterases. Lovastatin was the first compound identified as 
a promising bone anabolic agent after examining about 30,000 compounds [5]. Statins act as an anabolic agent by promoting bone formation in vitro and also in vivo in rodents after high oral doses [5-11]. Several observational clinical studies on patients treated with oral statins showed varying results. Some had suggested that oral statins minimize the risk of fractures and increase bone mineral density [1217], while others reported that they had no effects on bone [18-23]. Several clinical studies that compared bone biochemical markers between statin-treated patients and control populations have had varying outcomes [24-26]. However, these findings as a whole suggested that the oral statins do not have sufficient anabolic effects in vivo when given in cholesterol lowering doses. Therefore, high doses of statins are needed to protect the bone and induce bone formation in vivo. However, high doses of statins had been associated with myotoxicity and hepatotoxicity [27-29].

Tocotrienols and tocopherols are members of the vitamin E family. They are further subdivided into alpha, beta, gamma, and delta isomers. All the vitamin $\mathrm{E}$ isomers have antioxidant properties. In addition, tocotrienols have anticancer, neuroprotective, antiplatelet, and cholesterollowering activities [30]. Studies have shown that vitamin E, specifically the tocotrienols was able to maintain bone density and prevent further bone loss in different animal models of osteoporosis [31]. Recent studies offered evidence for tocotrienols as a bone anabolic agent in normal male, ovariectomised female and nicotine-treated male rats [3235]. Tocotrienols, similar to statins, suppress the activity of HMGCoA reductase (Figure 1), although through different mechanisms [36, 37]. Statins inhibit the enzyme activity through competitive inhibition, while tocotrienols modulate the intracellular mechanism of controlled degradation of the reductase protein $[38,39]$. A prior study revealed that only gamma and delta tocotrienols stimulate the degradation of HMGCoA reductase, and only the delta isomer was able to block the cleavage of sterol regulatory elementbinding proteins (SREBP) [39]. Therefore, administration of statins and delta-tocotrienol together may have synergistic or additive effects. Additionally, with coadministration of deltatocotrienol, we may be able to avoid the occurrence of the adverse effects of high doses of lovastatin in humans.

The annatto bean is one of the major sources of tocotrienols, containing $90 \%$ delta and 10\% gamma tocotrienols. The annatto tree is a tropical South American tree (Bixa Orellana), having spinose capsules with seeds and cordate leaves that yield annatto beans. A previous study reported that coadministration of a pure extract of annatto tocotrienols lowered the effective dose of lovastatin and offered a novel approach to cancer prevention and therapy [40]. Small daily doses of delta and gamma tocotrienols isolated from annatto bean reduced serum levels of cholesterol, triglycerides, and LDL by $15-20 \%$ [41]. Annatto-derived tocotrienol was chosen for this study due to the reported efficacy above, as well as the total absence of any tocopherol isomers in the extract. Tocopherol may interfere with tocotrienol absorption and distribution and may attenuate the inhibitory effect of delta-tocotrienol on liver HMGCoA reductase [42-44]. Previous studies have found that the tocopherol isomers do not prevent bone loss in orchidectomised rats $[45,46]$. Thus, it is important to use a tocopherol free extract in this study.

Ovariectomised rats are a widely accepted model of postmenopausal osteoporosis due to their appropriateness, convenience, and relevance. Furthermore, the ovariectomised rats exhibit skeletal response similar to postmenopausal women [47].

Biochemical markers of bone resorption and formation are sensitive markers that reflect the different processes involved in bone metabolism by detecting the activity of osteoclasts and osteoblasts. However, they do not show the changes in bone mass and structure [48, 49]. Osteocalcin is an osteoblast-specific noncollagenous protein. It forms about $10 \%$ of noncollagenous proteins of the bone matrix and generally serves as a specific marker for osteoblast activity and bone formation [50]. Cross-linked C-terminal (CTX) telopeptides are proteolytic fragments of type 1 collagen formed during bone resorption. CTX is known as a specific marker for osteoclast activity and bone resorption [51]. Static bone histomorphometric indices are used to examine bone histology and quantitatively evaluate the activity of the bone cells at a specific time. Therefore, a strong tool to study bone metabolism and bone morphology is through a combination of bone biochemical analysis and static histomorphometric indices.

The current study was designed to evaluate the combined effects of delta-tocotrienol and lovastatin and to compare it with delta-tocotrienol and lovastatin given individually on bone biomarkers and static bone histomorphometric parameters in the ovariectomised estrogendeficient female rat. The findings from this study may provide an alternative medication to treat postmenopausal osteoporosis.

\section{Method and Materials}

2.1. Animals. Forty eight female Sprague-Dawley rats that were approximately 3 months old and weighed 200-250 g, were purchased from the Laboratory Animal Research Unit, Universiti Kebangsaan Malaysia. The rats were kept two per cage under 12 hour light-dark cycles. The rats were fed commercial rat chow (Gold Coin, Selangor, Malaysia) and tap water ad libitum. After one week of acclimatization, the rats were randomly divided into 6 groups with 8 rats in each group. The first group, served as a baseline control (BC), was not ovariectomised and was sacrificed upon receipt. The second group was not ovariectomised but was sham-operated (SHAM) for simulation of surgical stress. The third group was the ovariectomised control group (OVXC). The fourth group was ovariectomised and treated with $11 \mathrm{mg} / \mathrm{kg}$ of lovastatin $(\mathrm{OVX}+\mathrm{LOV})$. The fifth was ovariectomised and treated with $60 \mathrm{mg} / \mathrm{kg}$ of deltatocotrienol $(\mathrm{OVX}+\mathrm{TT})$. And the sixth was ovariectomised and treated with $11 \mathrm{mg} / \mathrm{kg}$ of lovastatin and $60 \mathrm{mg} / \mathrm{kg}$ of delta-tocotrienol $(\mathrm{OVX}+\mathrm{TT}+\mathrm{LOV})$. The treatment had been administrated to the rats daily via oral gavage for 8 weeks. 


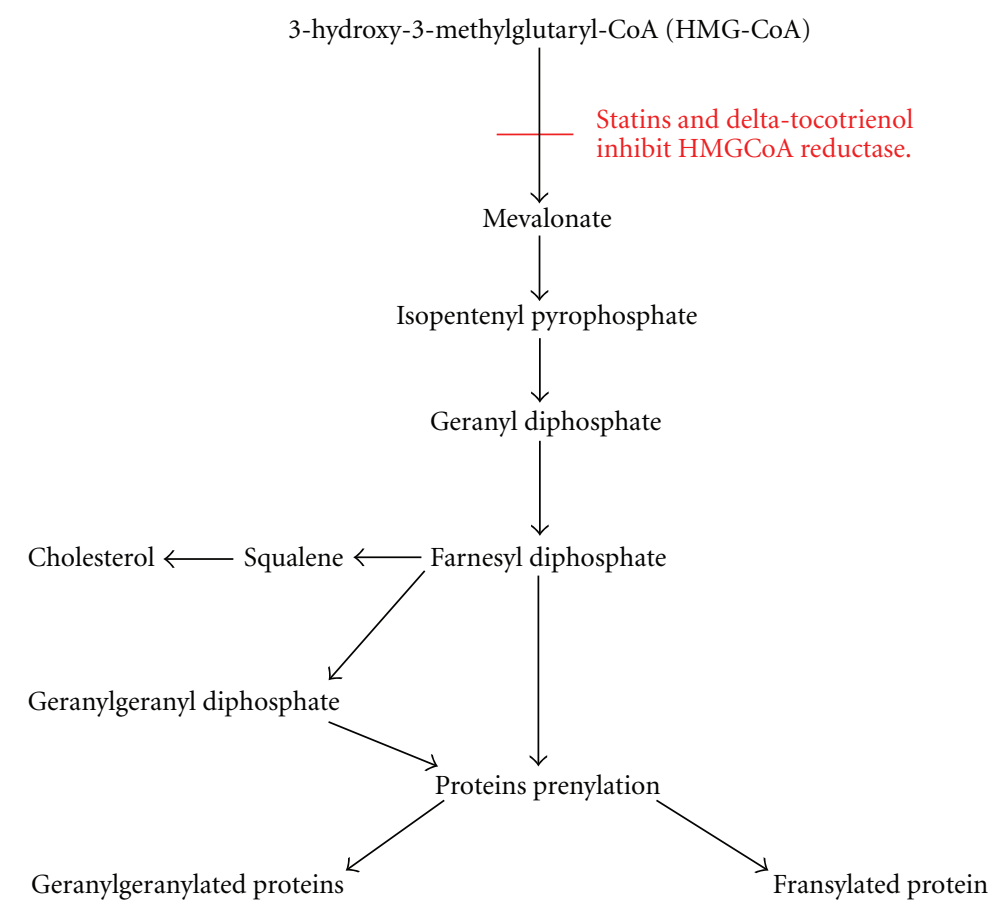

Figure 1: Mechanism of action of lovastatin and delta-tocotrienol on mevalonate pathway.

Prior approval for the study protocol had been obtained from the UKM Animal Ethics Committee, (PP/FAR/2011/ IMA/27-JANUARY/352-JANUARY-2011-DECEMBER2012).

2.2. Preparation of Treatment. The Delta Gold 70 viscous oil (American River Nutrition, Hadely, USA) is a rich deltatocotrienol extract from the annatto bean consisting of $90 \%$ delta-tocotrienol and 10\% gamma-tocotrienol. The orange-red oil was diluted in olive oil (Bertolli Classico, Italy) and administrated daily via oral gavage at a dose of $60 \mathrm{mg} / \mathrm{kg}$ delta-tocotrienol for 8 weeks. This dose was roughly equivalent to $420 \mathrm{mg} /$ day for an adult human.

Mevacor tablet, containing $40 \mathrm{mg}$ of lovastatin, was crushed and suspended in $0.5 \%$ carboxymethylcellulose (Sigma-Aldrich, St. Louis, USA) solution and given daily to rats via oral gavage at a dose of $11 \mathrm{mg} / \mathrm{kg}$ for 8 weeks. This dose was equivalent to $80 \mathrm{mg} /$ day for an adult human. Oral gavages of the vehicles were given to SHAM and OVX groups for a similar duration of treatment. The duration of the study was based on a previous study, in which 8 weeks was shown to be adequate for significant changes in bone parameters to be observed [52].

2.3. Sample Collection. For the biochemical study, blood samples were collected at the start (pretreatment) and after 8 weeks of treatment (posttreatment) from all the groups except BC because they were sacrificed upon receipt. Blood samples were obtained from the retroorbital vessel after the rat was anesthetized with diethyl ether. After 3 hours, blood was centrifuged for $10 \mathrm{~min}$ at $3000 \mathrm{rpm}$, and the serum stored at $-70^{\circ} \mathrm{C}$ for further use.
For bone histomorphometric analysis, the rats were sacrificed by high dose diethyl ether after completing the treatment period. The left femurs were removed and the distal portion kept in 70\% alcohol.

2.4. Biochemical Analysis. Levels of bone biochemical markers, osteocalcin and CTX in serum were measured using an ELISA microplate reader (VERSA max, Sunnyvale, USA). The kits used were Rat-Mid Osteocalcin ELISA kit (IDS, UK) and RatLaps CTX-1 ELISA kit (IDS, UK).

2.5. Bone Histomorphometry. The left femur was decalcified with EDTA (Sigma Aldrich, St. Louis, USA) for 2 months and then embedded in histological paraffin wax. The decalcified paraffin blocks were sectioned at $6 \mu \mathrm{m}$ with a microtome (Leica, Wetzlar, Germany) and stained with Hematoxylin and Eosin.

The static parameters, namely, osteoblast surface/bone surface (ObS/BS), osteoclast surface/bone surface $(\mathrm{OcS} / \mathrm{BS})$, eroded surface/bone surface (ES/BS), osteoid surface/bone surface (OS/BS), and osteoid volume/bone volume (OV/BV) were analysed using a quantitative stereological method for histology known as the Weibel technique.

The static histomorphometric indices were performed at the secondary spongiosa area, which is rich in trabecular bone. The selected metaphyseal region was located $1 \mathrm{~mm}$ from the lateral cortex and $3-7 \mathrm{~mm}$ from the lowest point of the growth plate.

Bone cellular average changes were analyzed and expressed using bone histomorphometric measurements as 


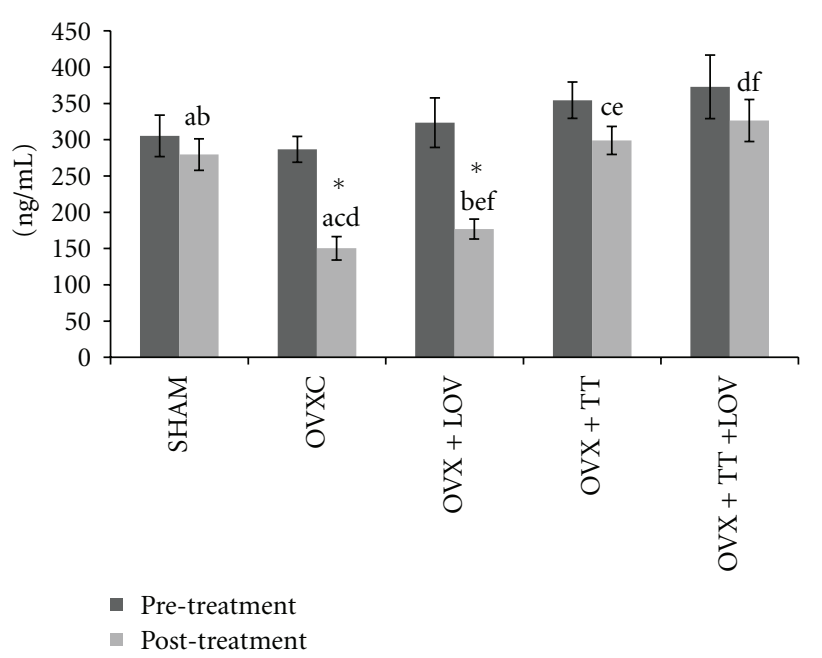

Figure 2: Serum osteocalcin levels in treatment groups. Data labeled with the same letter indicates significant difference between treatment groups. ${ }^{*}$ Indicates significant difference between pretreatment and posttreatment values for the same group. Data was presented as mean \pm SEM. Significant level was taken at $P<0.05$.

recommended by The American Society of Bone Mineral Research Histomorphometry Nomenclature Committee [53].

2.6. Statistical Analysis. Data analysis was performed using the Statistical Package for Social Sciences software (19, SPSS, Chicago, IL, USA). The Kolmgorov-Smirnov test was used as a normality test. The paired-sample $t$ test was utilized to compare the same group before and after treatment. The ANOVA followed by post hoc Tukey's tests were used to determine the statistical significance between groups. The results were expressed as mean values \pm standard error of the mean (SEM). The statistical differences were considered significant at $P<0.05$.

\section{Results}

Serum osteocalcin level was significantly lower posttreatment compared to pretreatment for the OVXC and OVX + LOV groups. The posttreatment level of serum osteocalcin did not differ significantly from the pre-treatment level for the remaining groups. No significant differences were seen between the groups before treatment. After treatment, the serum osteoclacin level in the OVXC group was significantly lower than the SHAM group. The OVX + TT and OVX + TT + LOV groups had significantly higher serum osteocalcin levels compared to the OVXC and OVX + LOV groups, but they did not differ from the SHAM group. While the OVX + LOV group did not differ significantly from the OVXC group but was significantly lower than the SHAM group (Figure 2).

Serum CTX level was significantly higher posttreatment compared to pretreatment for the OVXC group. The posttreatment level of serum CTX did not differ significantly

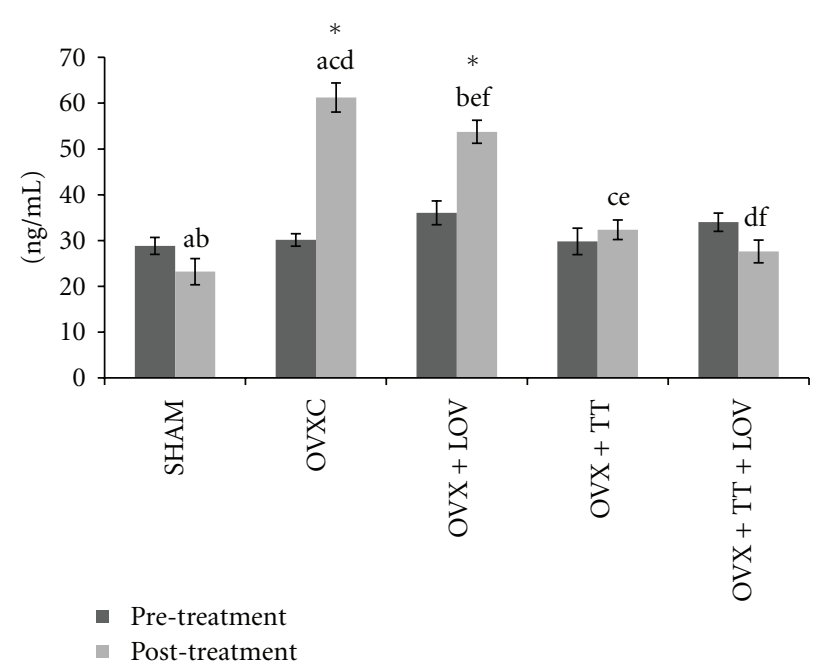

FIGURE 3: Serum CTX levels in treatment groups. Data labeled with the same letter indicates significant difference between treatment groups. ${ }^{*}$ Indicates significant difference between pretreatment and posttreatment values for the same group. Data was presented as mean \pm SEM. Significant level was taken at $P<0.05$.

from the pretreatment level for the remaining groups No significant differences were observed between the groups before treatment. After treatment the serum CTX level for the OVXC group was significantly higher than the SHAM group. The OVX + TT and OVX $+\mathrm{TT}+\mathrm{LOV}$ groups had significantly lower serum CTX levels compared to the OVXC and OVX + LOV groups, but they did not differ from the SHAM group. While the OVX + LOV group did not differ significantly from the OVXC group but was significantly higher than the SHAM group (Figure 3).

The OVXC group had significantly lower ObS/BS, OS/BS and $\mathrm{OV} / \mathrm{BV}$ values than the $\mathrm{BC}$ and SHAM groups (Figures 4 , $5,6,7$, and 8 ). There were no significant changes in all static bone parameters between the $\mathrm{BC}$ and SHAM groups. The $\mathrm{OVX}+\mathrm{TT}+\mathrm{LOV}$ group had significantly higher $\mathrm{ObS} / \mathrm{BS}$ and $\mathrm{OV} / \mathrm{BV}$ values compared to the OVX + TT group; significantly higher ObS/BS, OS/BS, and OV/BV values compared to OVX + LOV and OVXC groups; and significantly higher $\mathrm{ObS} / \mathrm{BS}, \mathrm{OS} / \mathrm{BS}$, and $\mathrm{OV} / \mathrm{BV}$ values than the $\mathrm{BC}$ and SHAM groups. The OVX + TT group had significantly higher $\mathrm{ObS} / \mathrm{BS}$, OS/BS, and OV/BV values compared to the OVX + LOV and OVXC groups, and significantly higher $\mathrm{ObS} / \mathrm{BS}, \mathrm{OS} / \mathrm{BS}$, and OV/BV values than the BC and SHAM groups. The OVX + LOV did not differ from the OVXC in all static bone parameters but had significantly lower ObS/BS, $\mathrm{OS} / \mathrm{BS}$, and $\mathrm{OV} / \mathrm{BV}$ values than the $\mathrm{BC}$ and SHAM groups (Figures 4, 5, 6, 7, and 8).

The OVXC group had significantly higher OcS/BS and ES/BS values than the $\mathrm{BC}$ and SHAM groups. The $\mathrm{OVX}+\mathrm{TT}+\mathrm{LOV}$ group had significantly lower OcS/BS value compared to the OVX + TT group; significantly lower $\mathrm{OcS} / \mathrm{BS}$ and ES/BS values compared to the OVX + LOV and OVXC groups; significantly lower OcS/BS value than the $\mathrm{BC}$ and SHAM groups; significantly lower ES/BS value than 


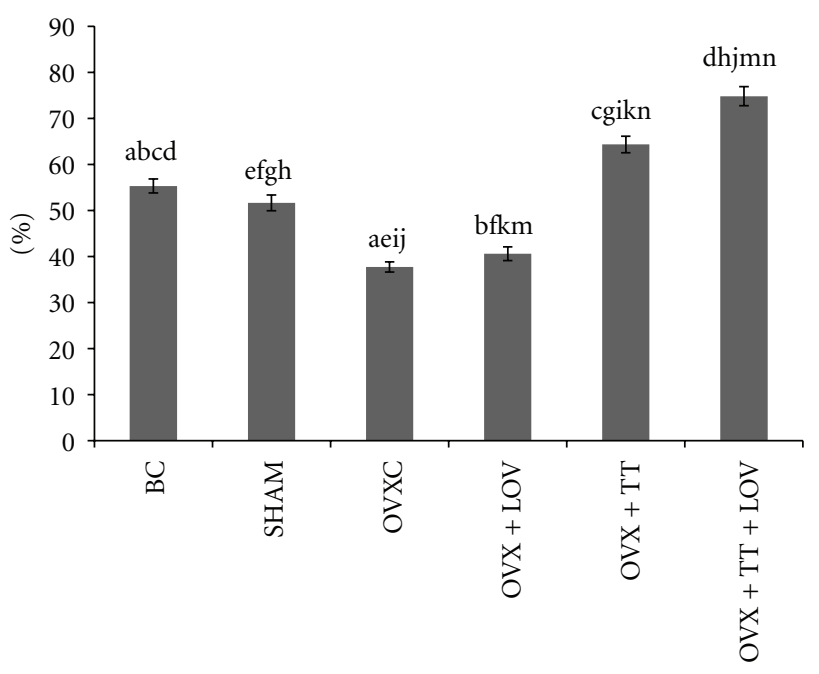

Figure 4: Osteoblast Surface/Bone Surface\% (ObS/BS\%) in treatment groups. Data labeled with the same letter indicates significant difference between treatment groups. Data was presented as mean \pm SEM. Significant level was taken at $P<0.05$.

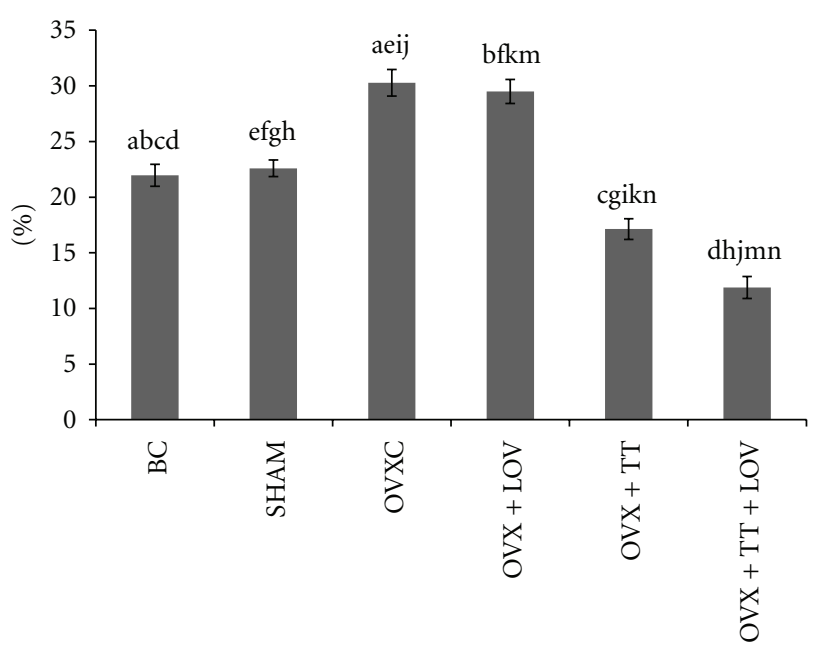

FIGURe 5: Osteoclast Surface/Bone Surface\% (OcS/BS\%) in treatment groups. Data labeled with the same letter indicates significant difference between treatment groups. Data was presented as mean \pm SEM. Significant level was taken at $P<0.05$.

the SHAM group. The OVX + TT group had significantly lower OcS/BS and ES/BS values compared to the OVX + LOV and OVXC groups; and significantly lower OcS/BS value than the BC and SHAM groups. The OVX + LOV group had significantly higher OcS/BS and ES/BS values than the BC and SHAM groups (Figures 4, 5, 6, 7, and 8).

\section{Discussion}

Both osteoblast and osteoclast cells are required for continuous bone remodeling. During bone formation, the osteoblast cells start to secrete osteoid and synthesize osteocalcin, while during bone resorption, the activated osteoclast cells dissolve

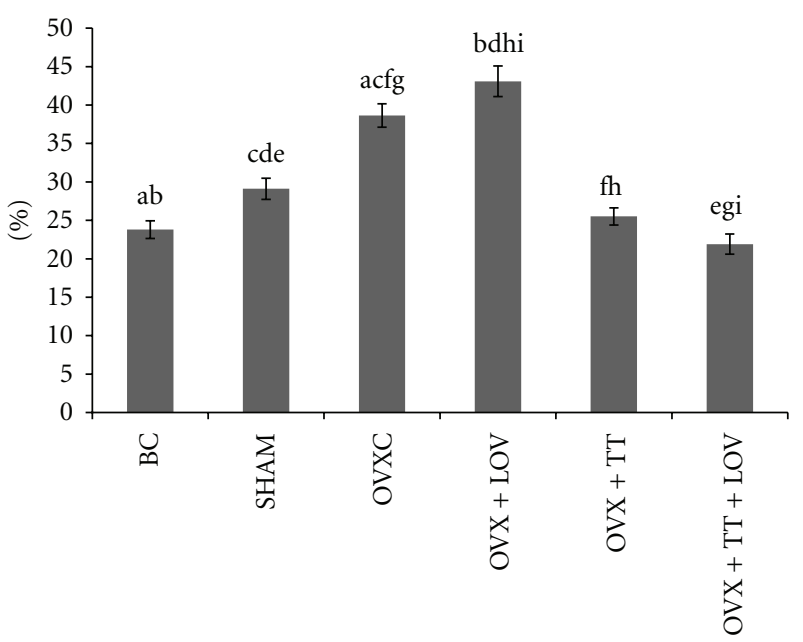

FIGURE 6: Eroded Surface/Bone Surface\% (ES/BS\%) in treatment groups. Data labeled with the same letter indicates significant difference between treatment groups. Data was presented as mean \pm SEM. Significant level was taken at $P<0.05$.

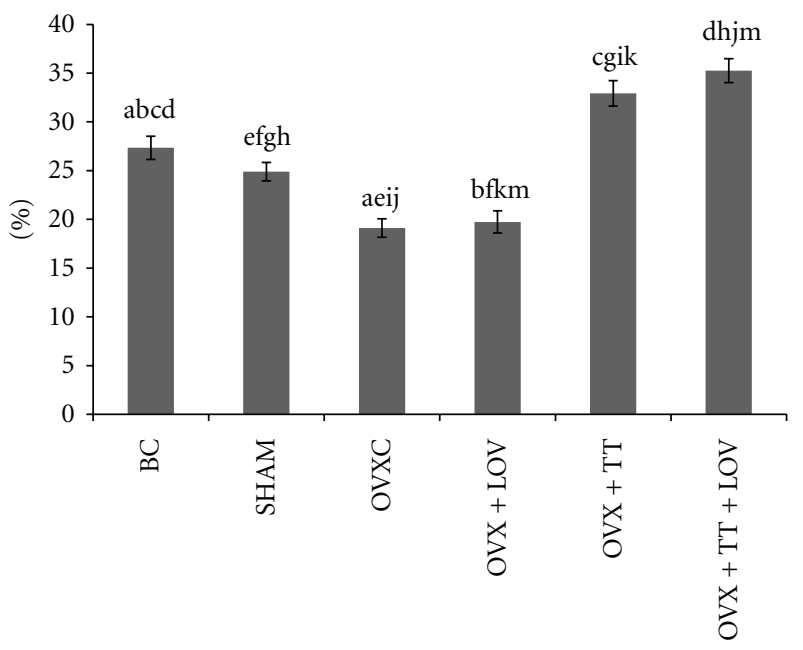

Figure 7: Osteoid Surface/Bone Surface\% (OS/BS\%) in treatment groups. Data labeled with the same letter indicates significant difference between treatment groups. Data was presented as mean \pm SEM. Significant level was taken at $P<0.05$.

the bone matrix resulting in the formation of the eroded surfaces and the release of CTX [54].

The results of the current study showed that daily supplementation of delta-tocotrienol in combination with lovastatin increased the osteoblastic bone formation and decreased osteoclastic bone resorption in ovariectomised rats as indicated by the OVX + TT + LOV group which had significantly higher serum osteocalcin, ObS/BS, OS/BS, and $\mathrm{OV} / \mathrm{BV}$ values and significantly lower serum CTX, OcS/BS, and ES/BS values compared to the OVXC group. The role of the mevalonate pathway in the pathophysiology of osteoporosis suggests that critical regulatory mechanisms are needed to maintain osteoblast and osteoclast function. Inhibition of the mevalonate pathway by statins and tocotrienols 


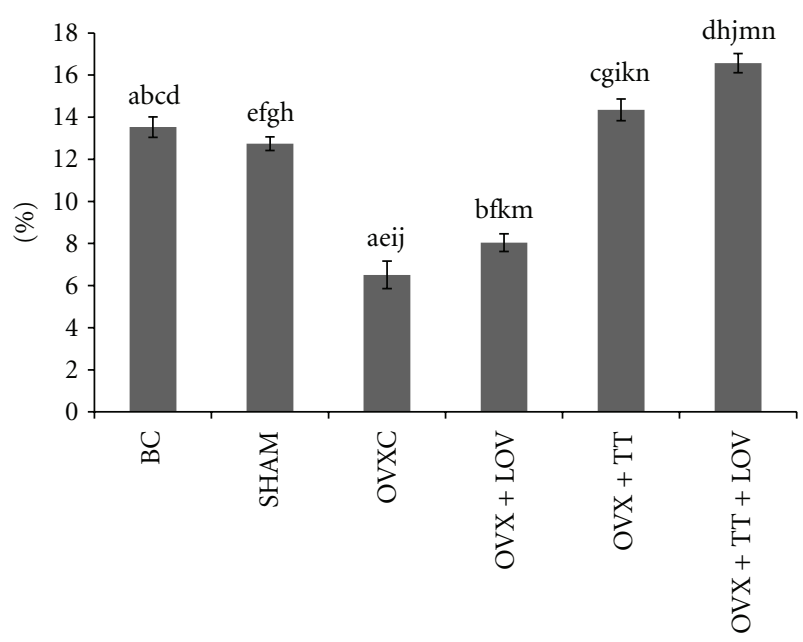

Figure 8: Osteoid Volume/Bone Volume\% (OV/BV\%) in treatment groups. Data labeled with the same letter indicates significant difference between treatment groups. Data was presented as mean \pm SEM. Significant level was taken at $P<0.05$.

(Figure 1) suppresses the prenylation of GTPase binding proteins and disrupts their function. Therefore, inhibition of GTPase function reduces the activity of osteoclasts and induces their apoptosis [5, 55-57]. Inhibition of GTPase function also increases osteoblast activity through enhancement of BMP-2 expression [5, 6, 57-60]. Ultimately, this will lead to stimulation of bone formation and decrease in bone resorption.

Competitive inhibition of HMGCoA reductase by statins reduces the cholesterol level. This reduction subsequently stimulates SREBP cleavage and inhibits HMGCoA reductase degradation, resulting in an increase in mRNA and HMGCoA reductase protein expression [61]. In contrast, deltatocotrienol inhibits the cleavage of SREBP and induces the degradation of HMGCoA reductase, thereby inducing the reduction in mRNA and protein HMGCoA reductase levels [61]. Therefore, the combination of lovastatin and deltatocotrienol may have synergistic or additive effects on bone metabolism, while at the same time avoiding the unwanted effects of high doses and low bioavailability of lovastatin.

The current study found that delta-tocotrienol combined with lovastatin provided better bone formation and bone protection against ovariectomy-induced bone loss compared to delta-tocotrienol alone as indicated by the OVX + TT + LOV group which had significantly higher $\mathrm{ObS} / \mathrm{BS}$, and OV/BV values and significantly lower OcS/BS value compared to the OVX + TT group. The improvement in bone metabolism by the combined treatment may be due to synergistic or additive inhibition of the mevalonate pathway. Moreover, the OVX + TT group had significantly higher serum osteocalcin, ObS/BS, OS/BS, and OV/BV values and significantly lower serum CTX, OcS/BS and ES/BS values compared to the OVXC group. These results were consistent with those who found that $60 \mathrm{mg} / \mathrm{kg}$ of tocotrienols had antiosteoporotic effects in thyroidectomised, orchidectomised, oxidative stressed, adrenalectomized, nicotine treated, and ovariectomised rat models [62-69]. The dose of $60 \mathrm{mg} / \mathrm{kg} /$ day for rats is roughly equivalent to $420 \mathrm{mg} /$ day for humans, taking into the account the metabolic rate of rodents is around ten times faster than that of humans. This dose is relatively low has no toxic effects. It had been reported that daily supplementation of $200 \mathrm{mg} / \mathrm{kg}$ palm vitamin E extract containing 18.43\% alpha-tocopherol, $14.62 \%$ alpha-tocotrienol, $32.45 \%$ gamma-tocotrienol, and $23.93 \%$ delta-tocotrienol has no toxic effects in female mice [70].

The current study showed that the combination of deltatocotrienol plus lovastatin increased bone formation and reduced bone loss compared to lovastatin alone as indicated by the OVX + TT + LOV group which had significantly higher serum osteocalcin level, ObS/BS, OS/BS, and OV/BV values and significantly lower serum CTX, OcS/BS, and ES/BS values compared to the OVX + LOV group. Moreover, there were no significant changes in all biochemical markers and static bone histomorphometric indices between the OVXC and OVX + LOV groups. Therefore, lovastatin alone failed to enhance bone formation and to prevent bone resorption in ovariectomised rats at clinically tolerable hypocholesterolemic doses. Statins have limited distribution to the peripheral tissues after oral administration [71]. Therefore, they yield uncertain results as bone anabolic agents when used in vivo at cholesterol lowering doses. Bjarnason et al. [26] reported that fluvastatin did not affect serum osteocalcin and serum and urinary CTX levels in postmenoposal women with osteoporosis and mild hypercholesterolemia when given in clinically relevant doses. A cross over clinical study showed that $40 \mathrm{mg} /$ day of atorvastatin had no effect on serum osteocalcin and CTX in type 2 diabetic men with baseline hypercholesterolemia compared to placebo [72]. Similar results were seen, when a randomized clinical trial measured the serum CTX concentration in hypercholesterolemic patients treated with $20-80 \mathrm{mg}$ /day of simvastatin [24]. Twenty $\mathrm{mg} /$ day of pravastatin did not affect the serum CTX level in hypercholesterolemic postmenopausal women [25]. Meta analysis of both observational studies and clinical trials of around 300,000 patients found that there was clinical benefit from the use of oral statins but there was no significant reduction in fracture incidence in older women [73]. Yao and his coworkers ascertained that the $0.3,0.6,3,6$, and $10 \mathrm{mg} / \mathrm{kg}$ of simvastatin for 60 days could not prevent or restore ovariectomy-induced osteoporosis [74]. On the other hand, previous studies showed that lovastatin and other statins enhanced bone formation and reduced bone resorption after high oral doses in rodents [5, 7-10]. This indicates that clinically nontolerable doses of oral statins are required to achieve successful prevention and treatment of osteoporosis. Myotoxicity and hepatotoxicity were associated with the high doses of oral statins [27-29]. In this study, $11 \mathrm{mg} / \mathrm{kg}$ of lovastatin was chosen, which if extrapolated to human is roughly equivalent to $80 \mathrm{mg} / \mathrm{day}$, the highest dose of lovastatin used as an antihyperlipidemic agent.

The results of the current study found that the $\mathrm{OVX}+\mathrm{TT}+\mathrm{LOV}$ group had significantly higher $\mathrm{ObS} / \mathrm{BS}$, 
OV/BV and OS/BS values and significantly lower OcS/BS and ES/BS values than the SHAM group. These current findings indicate that delta-tocotrienol in combination with lovastatin promoted better cellular bone histomorphometric parameters than the SHAM group, thus exhibiting bone anabolic effects. Therefore, the combined treatment has the potential to increase bone strength. Recently, tocotrienols were shown to have bone anabolic activity in ovariectomised female, intact male and nicotine-treated male rats [32-35], and these findings had been confirmed by the results of the current study (Figures 4, 5, 7, and 8). Therefore, combination of delta-tocotrienol plus lovastatin may have the ability to further improve the bone density in normal bone.

\section{Conclusion}

Supplementation of delta-tocotrienol in combination with oral statins at clinically acceptable doses has both bone antiosteoporotic and anabolic activity and was more effective than delta-tocotrienol and lovastatin given individually. Therefore, the combination of delta-tocotrienol plus lovastatin has the potential to be used as an anti-osteoporotic agent especially in patients who are at risk of both conditions, that is, osteoporosis and hypercholesterolemia. This is especially true for postmeanopausal women, and also for men of the older age group.

\section{Acknowledgments}

The authors would like to thank University Kebangsan Malaysia for the Grant FF-073-2011 used to fund this study. The authors would also like to thank American River Nutrition. Inc, USA for the gift of Delta-Gold 70 tocotrienols.

\section{References}

[1] C. Jochems, U. Islander, M. Erlandsson, M. Verdrengh, C. Ohlsson, and H. Carlsten, "Osteoporosis in experimental postmenopausal polyarthritis: the relative contributions of estrogen deficiency and inflammation," Arthritis Research \& Therapy, vol. 7, no. 4, pp. R837-843, 2005.

[2] N. E. Cusano, A. G. Costa, B. C. Silva, and J. P. Bilezikian, "Therapy of osteoporosis in men with teriparatid," Journal of Osteoporosis, vol. 2011, 7 pages, 2011.

[3] R. Hwang, E. J. Lee, M. H. Kim et al., "Calcyclin, a $\mathrm{Ca}^{2+}$ ion-binding protein, contributes to the anabolic effects of simvastatin on bone," The Journal of Biological Chemistry, vol. 279, no. 20, pp. 21239-21247, 2004.

[4] J. K. Liao and U. Laufs, "Pleiotropic effects of statins," Annual Review of Pharmacology and Toxicology, vol. 45, no. 1, pp. 89118, 2005.

[5] G. Mundy, R. Garrett, S. Harris et al., "Stimulation of bone formation in vitro and in rodents by statins," Science, vol. 286, no. 5446, pp. 1946-1949, 1999.

[6] T. Maeda, A. Matsunuma, T. Kawane, and N. Horiuchi, "Simvastatin promotes osteoblast differentiation and mineralization in MC3T3-E1 cells," Biochemical and Biophysical Research Communications, vol. 280, no. 3, pp. 874-877, 2001.

[7] H. Oxlund and T. T. Andreassen, "Simvastatin treatment partially prevents ovariectomy-induced bone loss while increasing cortical bone formation," Bone, vol. 34, no. 4, pp. 609-618, 2004.

[8] H. Oxlund, M. Dalstra, and T. T. Andreassen, "Statin given perorally to adult rats increases cancellous bone mass and compressive strength," Calcified Tissue International, vol. 69, no. 5, pp. 299-304, 2001.

[9] M. L. Ho, Y. H. Chen, H. J. Liao et al., "Simvastatin increases osteoblasts and osteogenic proteins in ovariectomized rats," European Journal of Clinical Investigation, vol. 39, no. 4, pp. 296-303, 2009.

[10] F. J. Maritz, M. M. Conradie, P. A. Hulley, R. Gopal, and S. Hough, "Effect of statins on bone mineral density and bone histomorphometry in rodents," Arteriosclerosis, Thrombosis, and Vascular Biology, vol. 21, no. 10, pp. 1636-1641, 2001.

[11] C. Song, Z. Guo, Q. Ma et al., "Simvastatin induces osteoblastic differentiation and inhibits adipocytic differentiation in mouse bone marrow stromal cells," Biochemical and Biophysical Research Communications, vol. 308, no. 3, pp. 458-462, 2003.

[12] C. J. Edwards, D. J. Hart, and T. D. Spector, "Oral statins and increased bone-mineral density in postmenopausal women," The Lancet, vol. 355, no. 9222, pp. 2218-2219, 2000.

[13] C. R. Meier, R. G. Schlienger, M. E. Kraenzlin, B. Schlegel, and H. Jick, "HMG-CoA reductase inhibitors and the risk of fractures," Journal of the American Medical Association, vol. 283, no. 24, pp. 3205-3210, 2000.

[14] D. Bauer, G. Mundy, S. Jamal et al., "Statin use, bone mass and fracture: an analysis of two prospective studies," Journal of Bone and Mineral Research, vol. 14, supplement 1, p. S179, 1999.

[15] P. S. Wang, D. H. Solomon, H. Mogun, and J. Avorn, "HMGCoA reductase inhibitors and the risk of hip fractures in elderly patients," Journal of the American Medical Association, vol. 283, no. 24, pp. 3211-3216, 2000.

[16] Y. S. Chung, M. D. Lee, S. K. Lee, H. M. Kim, and L. A. Fitzpatrick, "HMG-CoA reductase inhibitors increase BMD in type 2 diabetes mellitus patients," Journal of Clinical Endocrinology \& Metabolism, vol. 85, no. 3, pp. 1137-1142, 2000.

[17] K. A. Chan, S. E. Andrade, M. Boles et al., "Inhibitors of hydroxymethylglutaryl-coenzyme A reductase and risk of fracture among older women," The Lancet, vol. 355, no. 9222, pp. 2185-2188, 2000.

[18] J. A. Cauley, R. Jackson, M. Pettinger et al., "Statin use and bone mineral density (BMD)in older women: the Women's Health Initiative Study (WHI-OS)," Journal of Bone and Mineral Research, vol. 152, supplement, p. S155, 2000.

[19] Y. Wada, Y. Nakamura, and H. Koshiyama, "Lack of positive correlation between statin use and bone mineral density in Japanese subjects with type 2 diabetes," Archives of Internal Medicine, vol. 160, no. 18, pp. 2860-2865, 2000.

[20] T. P. Van Staa, S. Wegman, F. de Vries, B. Leufkens, and C. Cooper, "Use of statins and risk of fractures," Journal of the American Medical Association, vol. 285, no. 14, pp. 1850-1855, 2001.

[21] A. Z. LaCroix, J. A. Cauley, M. Pettinger et al., "Statin use, clinical fracture, and bone density in postmenopausal women: results from the Women's Health Initiative Observational Study," Annals of Internal Medicine, vol. 139, no. 2, pp. 97-104, 2003.

[22] A. Z. Lacroix, J. A. Cauley, and R. Jackson, "Does statin use reduce risk of fracture in postmenopausal women? results from the Womens' Health Initiative Observational Study 
(WHI-OS)," Journal of Bone and Mineral Research, vol. 15, supplement 1, p. S155, 2000.

[23] L. Rejnmark, N. H. Buus, P. Vestergaard et al., "Effects of simvastatin on bone turnover and BMD: a 1-year randomized controlled trial in postmenopausal osteopenic women," Journal of Bone and Mineral Research, vol. 19, no. 5, pp. 737-744, 2004.

[24] E. A. Stein, M. Farnier, J. Waldstreicher, M. Mercuri, and Simvastatin/Atorvastatin Study Group, "Effects of statins on biomarkers of bone metabolism: a randomised trial," Nutrition, Metabolism and Cardiovascular Diseases, vol. 11, no. 2, pp. 84-87, 2001.

[25] J. M. Mostaza, C. De la Piedra, M. D. Curiel, R. Peña, and C. Lahoz, "Pravastatin therapy increases procollagen I Nterminal propeptide (PINP), a marker of bone formation in post-menopausal women," Clinica Chimica Acta, vol. 308, no. 1-2, pp. 133-137, 2001.

[26] N. H. Bjarnason, B. J. Riis, and C. Christiansen, "The effect of fluvastatin on parameters of bone remodeling," Osteoporosis International, vol. 12 , no. 5 , pp. 380-384, 2001.

[27] I. Fuentes and C. Aguilera, "Myopathy secondary to the treatment with inhibitors of HMG-CoA reductase," Medicina Clinica, vol. 111, no. 18, pp. 700-704, 1998.

[28] P. B. Duell, W. E. Connor, and D. R. Illingworth, "Rhabdomyolysis after taking atorvastatin with gemfibrozil," The American Journal of Cardiology, vol. 81, no. 3, pp. 368-369, 1998.

[29] R. H. Jacobson, P. Wang, C. J. Glueck, and D. N. Jody, "Myositis and rhabdomyolysis associated with concurrent use of simvastatin and nefazodone," Journal of the American Medical Association, vol. 277, no. 4, pp. 296-297, 1997.

[30] B. B. Aggarwal, C. Sundaram, S. Prasad, and R. Kannappan, "Tocotrienols, the vitamin E of the 21st century: its potential against cancer and other chronic diseases," Biochemical Pharmacology, vol. 80, no. 11, pp. 1613-1631, 2010.

[31] A. S. Nazrun, M. Norazlina, M. Norliza, and S. Ima Nirwana, "Comparison of the effects of tocopherol and tocotrienol on osteoporosis in animal models," International Journal of Pharmacology, vol. 6, no. 5, pp. 561-568, 2010.

[32] H. Hermizi, O. Faizah, S. Ima-Nirwana, S. Ahmad Nazrun, and M. Norazlina, "Beneficial effects of tocotrienol and tocopherol on bone histomorphometric parameters in SpragueDawley male rats after nicotine cessation," Calcified Tissue International, vol. 84, no. 1, pp. 65-74, 2009.

[33] A. N. Shuid, Z. Mehat, N. Mohamed, N. Muhammad, and I. N. Soelaiman, "Vitamin E exhibits bone anabolic actions in normal male rats," Journal of Bone and Mineral Metabolism, vol. 28, no. 2, pp. 149-156, 2010.

[34] M. Z. Mehat, A. N. Shuid, N. Mohamed, N. Muhammad, and I. N. Soelaiman, "Beneficial effects of vitamin e isomer supplementation on static and dynamic bone histomorphometry parameters in normal male rats," Journal of Bone and Mineral Metabolism, vol. 28, no. 5, pp. 503-509, 2010.

[35] T. A. Ahmad, A. S. Nazrun, A. Rashid Nurul Hashimah et al., "Comparison of the effects of tocotrienol and estrogen on the bone markers and dynamic changes in postmenopausal osteoporosis rat model," Asian Journal of Animal and Veterinary Advances, vol. 7, no. 3, pp. 225-234, 2012..

[36] P. W. Sylvester, "Synergistic anticancer effects of combined $\gamma$ tocotrienol with statin or receptor tyrosine kinase inhibitor treatment," Genes and Nutrition, vol. 7, no. 1, pp. 63-74, 2011.

[37] P. W. Sylvester, A. Kaddoumi, S. Nazzal, and K. A. El Sayed, "The value of tocotrienols in the prevention and treatment of cancer," Journal of the American College of Nutrition, vol. 29, no. 3, supplement, pp. 324S-333S, 2010.

[38] R. A. Parker, B. C. Pearce, R. W. Clark, D. A. Gordon, and J. J. Wright, "Tocotrienols regulate cholesterol production in mammalian cells by post- transcriptional suppression of 3-hydroxy-3-methylglutaryl-coenzyme A reductase," The Journal of Biological Chemistry, vol. 268, no. 15, pp. 1123011238, 1993.

[39] B. L. Song and R. A. DeBose-Boyd, "Insig-dependent ubiquitination and degradation of 3-hydroxy-3- methylglutaryl coenzyme A reductase stimulated by $\delta$ - and $\gamma$-tocotrienols," The Journal of Biological Chemistry, vol. 281, no. 35, pp. 25054-25061, 2006.

[40] J. A. McAnally, J. Gupta, S. Sodhani, L. Bravo, and H. Mo, "Tocotrienols potentiate lovastatin-mediated growth suppression in vitro and in vivo," Experimental Biology and Medicine, vol. 232, no. 4, pp. 523-531, 2007.

[41] B. Tann and A. Mueller, Tocotrienols Vitamin E Beyond Tocopherols, AOCS/CRC, 2008.

[42] S. Ikeda, T. Tohyama, H. Yoshimura, K. Hamamura, K. Abe, and K. Yamashita, "Dietary $\alpha$-tocopherol decreases $\alpha$ tocotrienol but not $\gamma$-tocotrienol concentration in rats," Journal of Nutrition, vol. 133, no. 2, pp. 428-434, 2003.

[43] A. Shibata, K. Nakagawa, P. Sookwong, T. Tsuduki, A. Asai, and T. Miyazawa, " $\alpha$-Tocopherol attenuates the cytotoxic effect of $\delta$-tocotrienol in human colorectal adenocarcinoma cells," Biochemical and Biophysical Research Communications, vol. 397, no. 2, pp. 214-219, 2010.

[44] H. T. Khor and T. T. Ng, "Effects of administration of $\alpha$ tocopherol and tocotrienols on serum lipids and liver HMG CoA reductase activity," International Journal of Food Sciences and Nutrition, vol. 51, supplement, pp. S3-S11, 2000.

[45] S. C. Chai, C. I. Wei, K. Brummel-Smith, and B. H. Arjmandi, "The role of vitamin E in reversing bone loss," Aging —Clinical and Experimental Research, vol. 20, no. 6, pp. 521-527, 2008.

[46] F. Deyhim, C. Garcia, A. Villareal et al., "Vitamin E does not support bone quality in orchidectomized rats," Current Issues in Food and Nutrition, vol. 3, no. 4, pp. 300-303, 2007.

[47] R. T. Turner, A. Maran, S. Lotinun et al., "Animal models for osteoporosis," Reviews in Endocrine \& Metabolic Disorders, vol. 2, no. 1, pp. 117-127, 2001.

[48] S. M. Weisman and V. Matkovic, "Potential use of biochemical markers of bone turnoverfor assessing the effect of calcium supplementation and predicting fracture risk," Clinical Therapeutics, vol. 27, no. 3, pp. 299-308, 2005.

[49] J. E. Compston and P. I. Croucher, "Histomorphometric assessment of trabecular bone remodelling in osteoporosis," Bone and Mineral, vol. 14, no. 2, pp. 91-102, 1991.

[50] E. Dogan and C. Posaci, "Monitoring hormone replacement therapy by biochemical markers of bone metabolism in menopausal women," Postgraduate Medical Journal, vol. 78, no. 926, pp. 727-731, 2002.

[51] S. D. Vasikaran, "Utility of biochemical markers of bone turnover and bone mineral density in management of osteoporosis," Critical Reviews in Clinical Laboratory Sciences, vol. 45, no. 2, pp. 221-258, 2008.

[52] S. Ima-Nirwana, M. Norazlina, and B. A. K. Khalid, "Pattern of bone mineral density in growing male and female rats after gonadectomy," Journal of the Asean Federation of Endocrine Society, vol. 16, pp. 21-36, 1998.

[53] A. M. Parfitt, M. K. Drezner, F. H. Glorieux et al., "Bone histomorphometry: standardization of nomenclature, symbols, 
and units: report of the asbmr histomorphometry nomenclature committee," Journal of Bone and Mineral Research, vol. 2, no. 6, pp. 595-610, 1987.

[54] B. Clarke, "Normal bone anatomy and physiology," Clinical Journal of the American Society of Nephrology, vol. 3, supplement 3, pp. S131-S139, 2008.

[55] W. A. Grasser, A. P. Baumann, S. F. Petras et al., "Regulation of osteoclast differentiation by statins," Journal of Musculoskeletal Neuronal Interactions, vol. 3, no. 1, pp. 53-62, 2003.

[56] A. Dudakovic, A. J. Wiemer, K. M. Lamb, L. A. Vonnahme, S. E. Dietz, and R. J. Hohl, "Inhibition of geranylgeranyl diphosphate synthase induces apoptosis through multiple mechanisms and displays synergy with inhibition of other isoprenoid biosynthetic enzymes," Journal of Pharmacology and Experimental Therapeutics, vol. 324, no. 3, pp. 1028-1036, 2008.

[57] U. N. Das, "Nitric oxide as the mediator of the antiosteoporotic actions of estrogen, statins, and essential fatty acids," Experimental Biology and Medicine, vol. 227, no. 2, pp. 88-93, 2002.

[58] I. R. Garrett, G. Gutierrez, and G. R. Mundy, "Statins and bone formation," Current Pharmaceutical Design, vol. 7, no. 8, pp. 715-736, 2001.

[59] I. R. Garrett and G. R. Mundy, "The role of statins as potential targets for bone formation," Arthritis Research and Therapy, vol. 4, no. 4, pp. 237-240, 2002.

[60] P. Y. Chen, J. S. Sun, Y. H. Tsuang, M. H. Chen, P. W. Weng, and F. H. Lin, "Simvastatin promotes osteoblast viability and differentiation via Ras/Smad/Erk/BMP-2 signaling pathway," Nutrition Research, vol. 30, no. 3, pp. 191-199, 2010.

[61] J. L. Goldstein, R. A. DeBose-Boyd, and M. S. Brown, "Protein sensors for membrane sterols," Cell, vol. 124, no. 1, pp. 35-46, 2006.

[62] S. Ima-Nirwana and S. Suhaniza, "Effects of tocopherols and tocotrienols on body composition and bone calcium content in adrenalectomized rats replaced with dexamethasone," Journal of Medicinal Food, vol. 7, no. 1, pp. 45-51, 2004.

[63] N. S. Ahmad, B. A. K. Khalid, D. A. Luke, and S. Ima-Nirwana, "Tocotrienol offers better protection than tocopherol from free radical-induced damage of rat bone," Clinical and Experimental Pharmacology and Physiology, vol. 32, no. 9, pp. 761770, 2005.

[64] S. Ima-Nirwana, A. Kiftiah, T. Sariza, M. T. Gapor, and B. A. K. Khalid, "Palm vitamin E improves bone metabolism and survival rate in thyrotoxic rats," General Pharmacology, vol. 32, no. 5, pp. 621-626, 1999.

[65] M. Norazlina, P. L. Lee, H. I. Lukman, A. S. Nazrun, and S. Ima-Nirwana, "Effects of vitamin E supplementation on bone metabolism in nicotine-treated rats," Singapore Medical Journal, vol. 48, no. 3, pp. 195-199, 2007.

[66] M. Norazlina, H. Hermizi, O. Faizah, and S. Ima-Nirwana, "Vitamin E reversed nicotine-induced toxic effects on bone biochemical markers in male rats," Archives of Medical Science, vol. 6, no. 4, pp. 505-512, 2010.

[67] S. Ima-Nirwana, M. Norazlina, and B. A. K. Khalid, "Palm vitamin E prevents osteoporosis in orchidectomized growing male rats," Natural Product Sciences, vol. 6, no. 4, pp. 155-160, 2000.

[68] S. Ima-Nirwana and H. Fakhrurazi, "Palm vitamin E protects bone against dexamethasone-induced osteoporosis in male rats," Medical Journal of Malaysia, vol. 57, no. 2, pp. 136-144, 2002.
[69] M. Norazlina, S. Ima-Nirwana, M. T. Gapor, and B. A. K. Khalid, "Palm vitamin $\mathrm{E}$ is comparable to $\alpha$-tocopherol in maintaining bone mineral density in ovariectomised female rats," Experimental and Clinical Endocrinology and Diabetes, vol. 108, no. 4, pp. 305-310, 2000.

[70] S. Ima-Nirwan, Y. Nurshazwan, A. S. Nazrun, M. Norliza, and M. Norazlina, "Subacute and subchronic toxicity studies of palm vitamin E in mice," Journal of Pharmacology and Toxicology, vol. 6, no. 2, pp. 166-173, 2011.

[71] B. A. Hamelin and J. Turgeon, "Hydrophilicity/lipophilicity: relevance for the pharmacology and clinical effects of HMGCoA reductase inhibitors," Trends in Pharmacological Sciences, vol. 19, no. 1, pp. 26-37, 1998.

[72] G. D. Braatvedt, W. Bagg, G. Gamble, J. Davidson, and I. R. Reid, "The effect of atorvastatin on markers of bone turnover in patients with type 2 diabetes," Bone, vol. 35, no. 3, pp. 766770, 2004.

[73] D. C. Bauer, G. R. Mundy, S. A. Jamal et al., "Use of statins and fracture: results of 4 prospective studies and cumulative metaanalysis of observational studies and controlled trials," Archives of Internal Medicine, vol. 164, no. 2, pp. 146-152, 2004.

[74] W. Yao, R. Farmer, R. Cooper et al., "Simvastatin did not prevent nor restore ovariectomy-induced bone loss in adult rats," Journal of Musculoskeletal Neuronal Interactions, vol. 6, no. 3, pp. 277-283, 2006. 


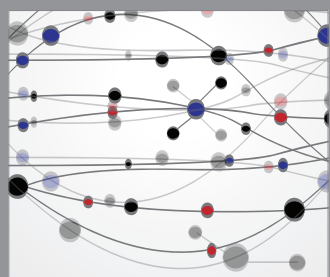

The Scientific World Journal
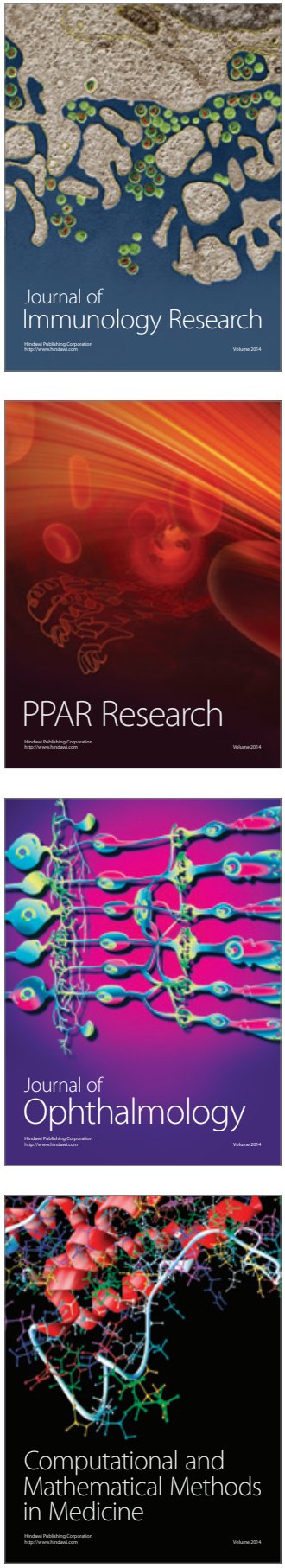

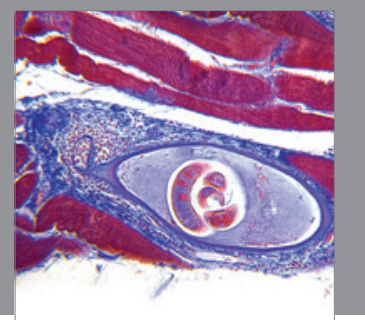

Gastroenterology

Research and Practice
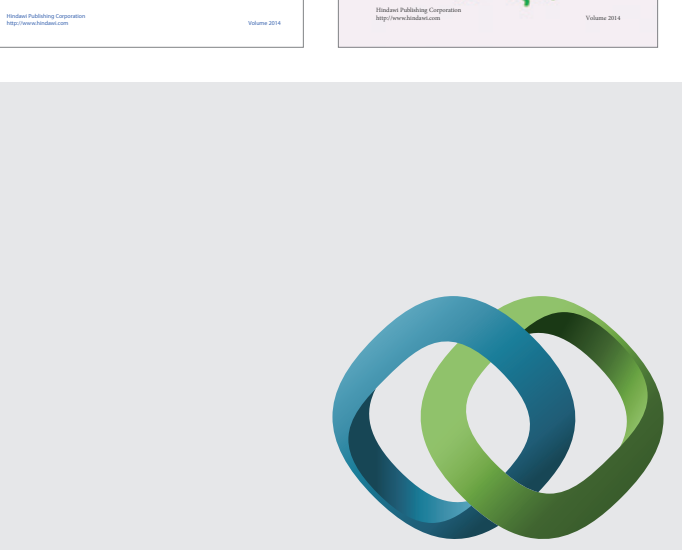

\section{Hindawi}

Submit your manuscripts at

http://www.hindawi.com
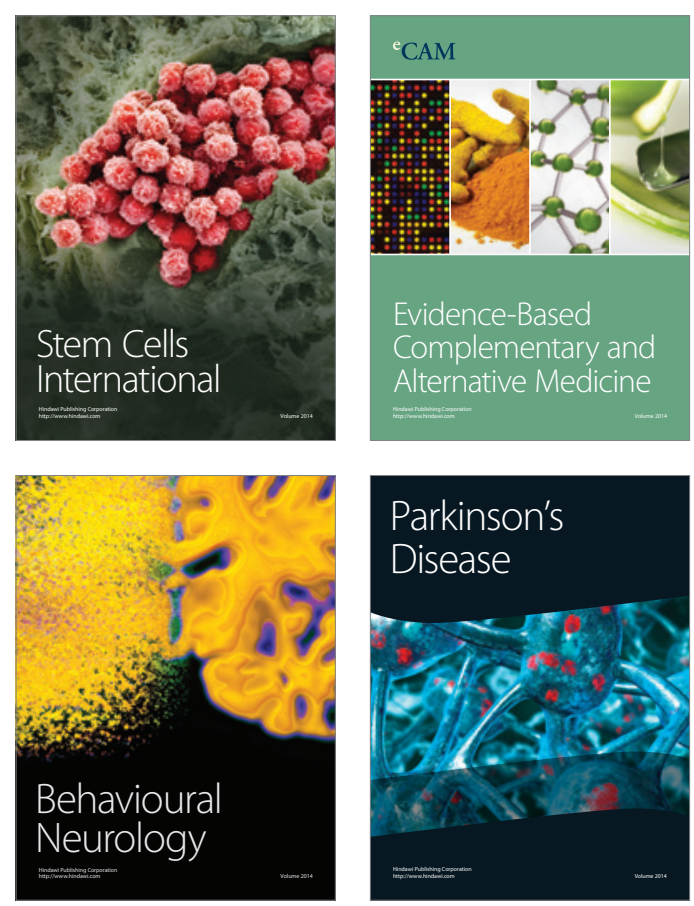

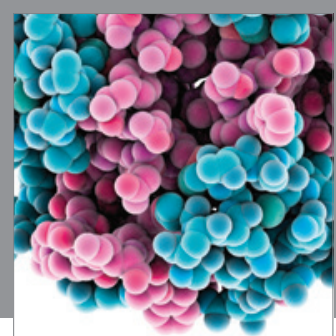

Journal of
Diabetes Research

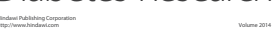

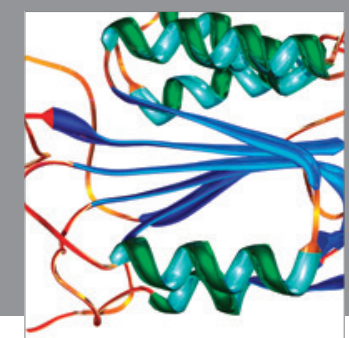

Disease Markers
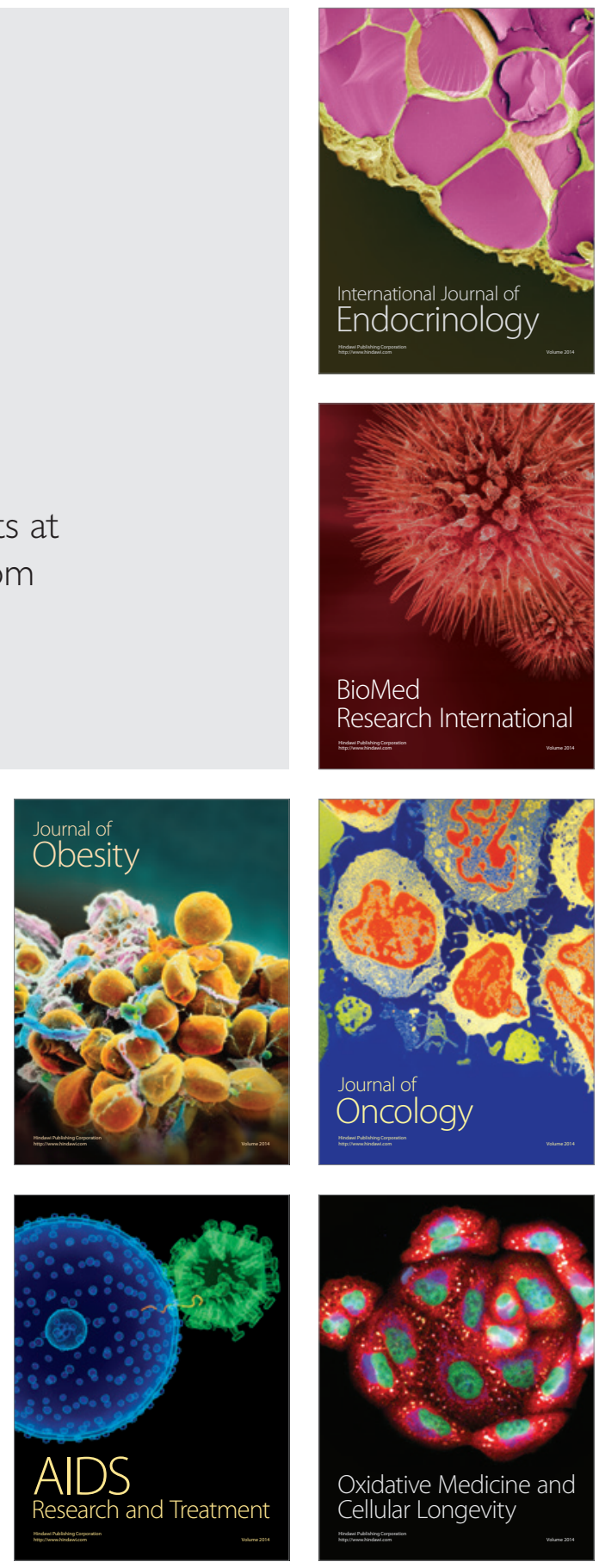